\title{
Large lymphangiomatous polyp present in palatine tonsil: a case report
}

\author{
G. Soundara Rajan, D. Senthamarai Kannan, \\ Veerasigamani Narendrakumar*, Arya N. Baby
}

Department of Otorhinolaryngology, Chengalpattu Medical College, Chengalpattu, Tamil Nadu, India

Received: 30 December 2019

Accepted: 09 June 2020

\section{*Correspondence:}

Dr. Veerasigamani Narendrakumar,

E-mail: drnarenkapv@yahoo.com

Copyright: (c) the author(s), publisher and licensee Medip Academy. This is an open-access article distributed under the terms of the Creative Commons Attribution Non-Commercial License, which permits unrestricted non-commercial use, distribution, and reproduction in any medium, provided the original work is properly cited.

\begin{abstract}
Lymphangiomatous polyps are rare tumours present in head and neck. Squamous papilloma accounts for majority of benign lesions, whereas vascular tumours are rarely reported. Tonsillar lymphangiomatous polyp is an uncommon hamartomatous lesion that generally arise from tonsillar surface. We present a case of young adolescent female with right tonsillar mass, tonsillectomy performed and post operatively found to be lymphangiomatous polyp, which has been rarely reported.
\end{abstract}

Keywords: Lymphangioma, Tonsil, Palatine tonsil, Hamartoma

\section{INTRODUCTION}

Lymphangiomatous polyps of the tonsil are benign tumours or rare hamartomatous lesions usually arise from tonsillar surface. ${ }^{1}$ It is also called as lymphoid polyp, hamartomata's tonsillar polyp or polypoid lymphangioma. ${ }^{2}$ This polyp is composed of stroma and covering epithelium. Stroma consists of loose to dense areolar tissue, dilated lymphatic channels and lymphoid tissue. ${ }^{3}$ Patients usually present with foreign body sensation in throat or dysphagia. In literature, only less than 30 cases reported ${ }^{4}$. In this paper, we report an extremely rare case of a very large lymphangiomatous polyp arising from tonsil in a pediatric patient which was unique from previous cases.

\section{CASE REPORT}

A 13 year old female child presented with history of dysphagia for one month duration. She also had complaints of foreign body sensation in throat. There was no history of any chronic illness or similar illness in her family members. Examination of oropharynx revealed a pedunculated, smooth, pale mass arising from medial surface of right palatine tonsil. There was no cervical lymphadenopathy. Blood parameters were within normal limits. USG abdomen was also normal. CT neck showed heterogeneously enhancing mass arising from base of tongue. Bilateral tonsillectomy was done under general anaesthesia. Grossly $5.5 \times 3 \times 1 \mathrm{~cm}$, polypoidal globular mass attached to the medial surface of right with a slender stalk which was firm in consistency, cut surface was smooth and white to tan. Histopathology report showed stratified squamous epithelium with underlying fibro collagenous tissue with lymphocytic infiltrates shows thin walled vascular spaces favouring the diagnosis of lymphangiomatous polyp. Postoperative period was uneventful for 3 months of follow up.

\section{DISCUSSION}

Lymphangiomatous polyp of the tonsil are uncommon benign tumours which are arising from medial surface of the tonsil, and are projecting in to the oropharynx with a small slender stalk. ${ }^{1,5}$ Usually these tumours are under recognized or under reported. So, its incidence is not known currently. Most of the published cases are adults. ${ }^{1}$ Only few cases are reported in children. 


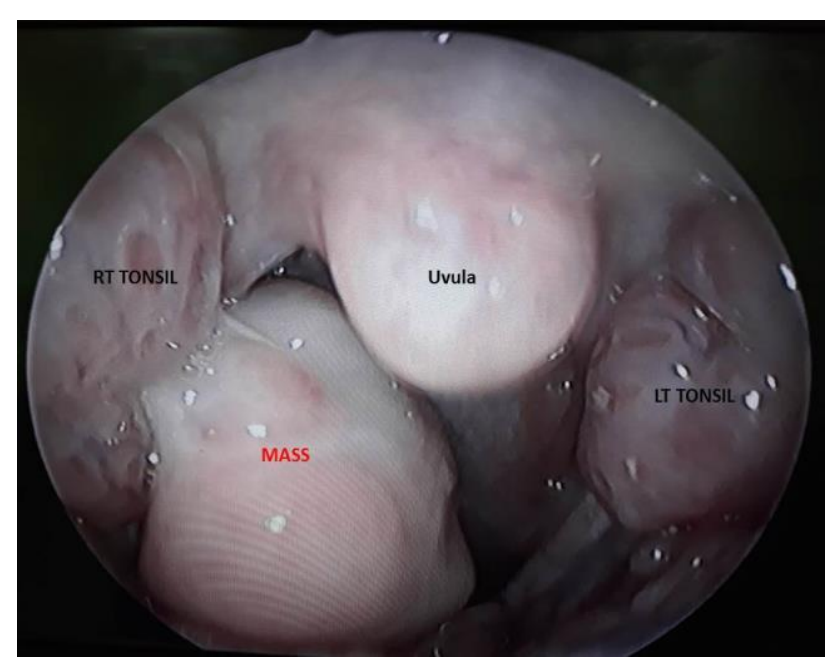

Figure 1: Large polyp arising from right tonsil.
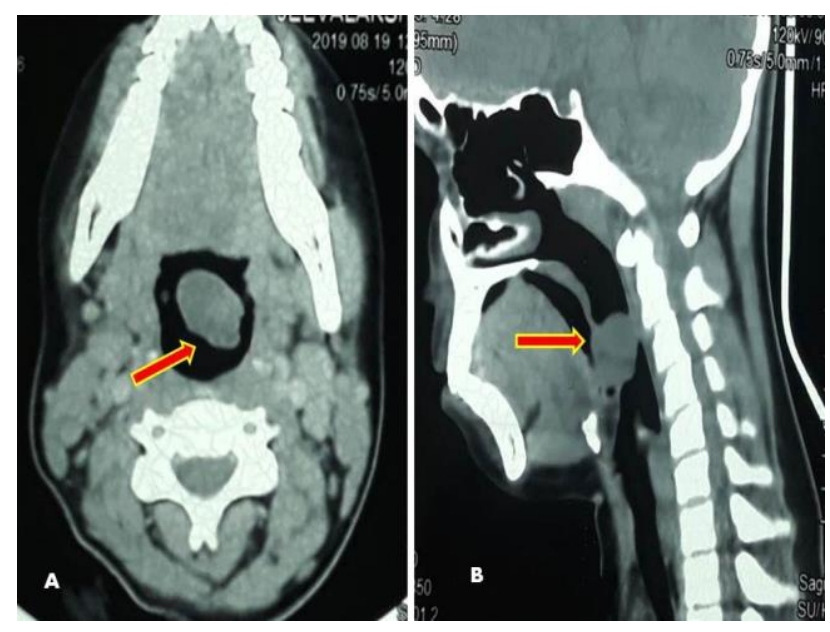

Figure 2: CT neck, (A) axial view, (B) saggital view.

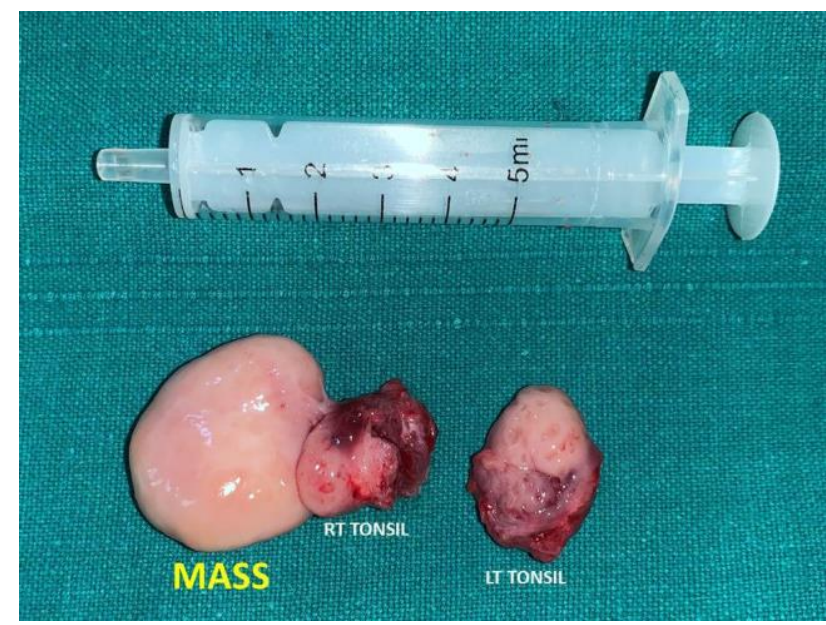

Figure 3: Specimen with both tonsils.

There are many theories suggested for its pathogenesis. First theory says that lymphangioma arises due to sequestration of lymphatic tissue derived from primitive sacs, which retain their rapid and proliferative growth potential but fail to join the major lymph sac of the body ${ }^{6,7}$ Second theory says that it arises from endothelial fibrillar membranes, which sprout from the walls of the cyst and penetrate to the surrounding tissue, then canalize and produce more cysts along the line of least resistance. So they grow in an uncontrolled disorderly manner with a tendency to penetrate normal anatomic structures. This uncontrolled proliferation is caused by dysregulation of growth factors like vascular endothelial growth factor (VEGF-C) and Prox $-1 .{ }^{6}$

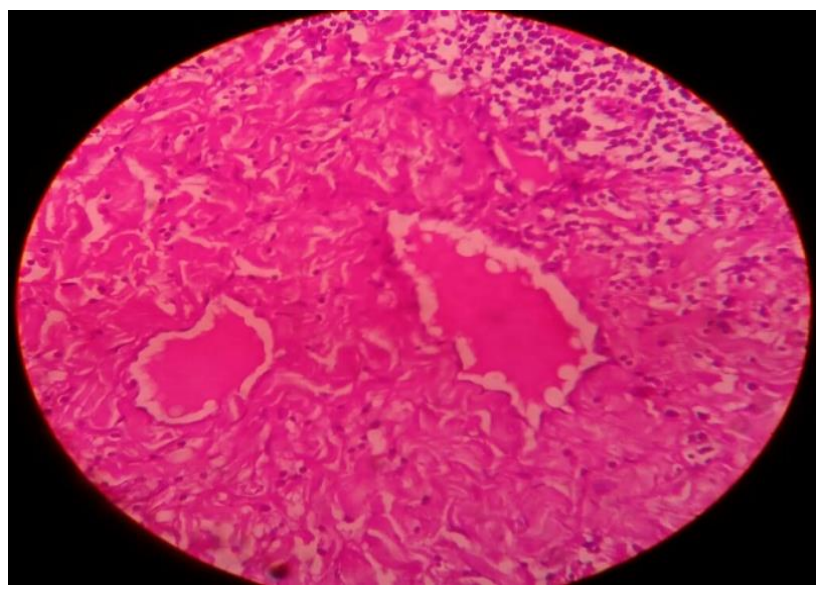

Figure 4: Histopathology-stratified squamous epithelium with underlying fibro collagenous tissue with lymphocytic infiltrates shows thin walled vascular spaces.

Clinical features of lymphangiomatous polyp are dysphagia, foreign body sensation in throat, sore throat, tonsillitis and tonsillar mass. When the mass is very large, it can affect surrounding vital structures to produce rhinolalia clausa, respiratory difficulty, stridor, excessive saliva etc. ${ }^{7}$

Histopathologically lympahngiomatous polyp consist of dilated lymphatic channels with stroma containing various amounts of fibrous, lymphoid, and adipose tissue. Intra luminal lymphocytes are also seen. Since these elements are normally found in the tonsillar fossa, but arranged in a different pattern, lymphangiomatous polyp are likely hamartomatous proliferations rather than true neoplasms. ${ }^{5}$

Differential diagnoses of mass lesions arising from tonsil are hemangioma, lymphangiectasia, hemangioma, fibro epithelial polyp, juvenile angiofibroma and papilloma. ${ }^{6}$ Treatment of choice of lymphangiomatous polyp is tonsillectomy although some authors suggest that only excision of the polypoid mass may be the only necessary procedure. $^{8}$

\section{CONCLUSION}

Lymphangiomatous polyps of the tonsil are uncommon benign lesions appearing in the palatine tonsil. Our case is unique because it is presented as a very large mass in a pediatric age group. Most common symptoms are 
dysphagia and foreign body sensation in throat. Tonsillectomy is the treatment of choice.

Funding: No funding sources

Conflict of interest: None declared

Ethical approval: Not required

\section{REFERENCES}

1. Ryu HS, Jung SY, Koh JS, Lee SS. Tonsillar lymphangiomatous polyp. Korean J Pathol. 2006;403:381-4.

2. Kardon DE, Weing BM, Heffner DK, Lester DR, Thompson MD. Tonsillar lymphangiomatous polyps: a clinic pathologic series of 26 cases. Modern Pathol. 2000;13:1128-33.

3. Sayar H, Sayar C, Adamhasan F, Uguz A. Lymphangiomatous polyp of tonsil: a case report. Turkish J Pthol. 2016;32(2):1119-21.

4. Cengiz BP, Acar M, Giritli E. A pedunculated lymphangiomatous polyp of the palatine tonsil. A case report. Braz J Otorhinolaryngol. 2013;79(3):402.
5. Heffner DK. Pathology of the tonsil and adenoids. Otolaryngol Clin North Am. 1987;20(2):279-86.

6. Iliadou E, Papapetropoulos N, Karamatzanis E, Saravakos P, Saravakos K. Primary Lymphangioma of the Palatine Tonsil in a 9-Year-Old Boy: A Case Presentation and Literature Review. Case Rep Otolaryngol. 2016;2016:1505202.1-3.

7. Chen HH, Lovell MA, Chan KH. Bilateral lymphangiomatous polyps of the palatine tonsils. Int J Pediatr Otolaryngol. 2010;74(1):87-8,

8. Park E, Pransky SM, Malicki DM, Hong P. Unilateral lymphangiomatous polyp of the palatine in a very young child: a clinicopathologic case report. Case Rep Pediatr. 2011;2011:451542.

Cite this article as: Rajan GS, Kannan DS, Narendrakumar V, Baby AN. Large lymphangiomatous polyp present in palatine tonsil: a case report. Int $\mathbf{J}$ Otorhinolaryngol Head Neck Surg 2020;6:1351-3. 